\title{
Effect on Drug Utilization and Expenditures of a Cost-Share Change From Copayment to Coinsurance
}

\author{
Donald G. Klepser, PhD, MBA; Jeffrey R. Huether, PharmD; Lee J. Handke, PharmD, MBA; \\ and Clint E. Williams, PharmD, MBA
}

\begin{abstract}
BACKGROUND: While increases in prescription drug spending have moderated in recent years, drug spending is still a concern among managed care organizations and health plan administrators. In order to minimize cost increases from year to year, many health care plans have shifted more of the cost of medications to the member-consumer. Coinsurance, a benefit design in which the patient pays a percentage of the cost of the medication, is garnering more attention as a type of cost-sharing that differs from the traditional copayment model.
\end{abstract}

OBJECTIVE: To estimate the impact on medication expenditures and utilization of a pharmacy benefit design change from 3-tier copayment to coinsurance.

METHODS: Drug expenditures and utilization of beneficiaries aged $\geq 18$ years and continuously enrolled in 2 privately insured groups were compared before and after a benefit design change in 1 of the groups. For the 12 months before the benefit design change, both groups had a 3-tier, fixed-dollar copayment structure with identical cost-sharing per 30-day supply: \$10 tier-1 copayment for generic drugs, \$25 tier-2 copayment for preferred brand drugs, and $\$ 40$ tier-3 copayment for non-preferred brand drugs. On September 1, 2005, a 4-tier coinsurance benefit design $(25 \%$ for all tiers except tier-3 [non-preferred] drugs at $50 \%$, with minimum and maximum patient out-of-pocket [0OP] cost applied to each tier) was implemented in the intervention group $(\mathrm{N}=46,311)$. The 3-tier copayment design was maintained in the comparison group $(\mathrm{N}=7,916)$. A differencein-difference analysis was used to estimate the effect of the benefit design change on expenditures and utilization, overall (for all prescription drugs), and for 3 classes of essential medications: antihypertensives, antidepressants, and statins. Analyses measured changes in outcomes from 6 months pre-change (October 1, 2004, through March 31, 2005) through 6 months post-change (0ctober 1,2005 , through March 31,2006$)$. In the overall (all drug) analyses, per member per month (PMPM) outcome measures were total pharmacy claims and cost, beneficiary (patient 00P) cost, and employer (plan sponsor) cost. Analyses of the 3 essential drug classes were limited to members with at least 1 claim in the drug class in both the pre-change and post-change periods ( $N=11,917$, intervention group; 1,792 , comparison group), and assessed per patient per month (PPPM) days supply, beneficiary cost, employer cost, and total cost.

RESULTS: Beneficiaries in the intervention group paid $31.8 \%$ of total pharmacy benefit cost at the point of care versus $31.5 \%$ in the comparison group in the post-change period. The increases in beneficiary cost from the pre-change period to the post-change period were not significantly different for the intervention $(7.5 \%)$ and comparison $(3.0 \%)$ groups $(P=0.983)$. From the pre-change period to the post-change period, total spending per member increased \$4.57 PMPM (6.3\%), from \$72.29 to \$76.87 in the intervention group versus a \$5.87 PMPM increase (9.5\%), from \$61.54 to $\$ 67.41$, in the comparison group, a relative difference of \$1.30 PMPM $(P=0.013)$. The increases in utilization from the pre-change period to the post-change period were not significantly different in the intervention group (2.4\%) versus the comparison group $(4.6 \%, P=0.189)$. Utilization per patient in the 3 essential drug classes increased $4.1 \%$ (1.59 days PPPM) in the intervention group versus $9.0 \%$ ( 3.23 days PPPM) in the comparison group $(P=0.004)$. Total expenditures in the 3 classes for the intervention and comparison groups increased $8.2 \%$ (\$5.07 PPPM) and 13.3\% $(\$ 7.80$ PPPM), respectively, a difference of $\$ 2.73$ PPPM $(P=0.003)$. Beneficiary cost for all 3 drug classes increased \$2.20 PPPM (9.2\%) in the intervention group versus $\$ 2.12$ PPPM $(9.1 \%)$ in the comparison group $(P=0.032)$. The increases in employer cost for the 3 essential drug classes in the intervention group (7.5\%, \$2.86 PPPM) and comparison group (16.1\%, \$5.67 PPPM) did not significantly differ $(P=0.057)$.

CONCLUSIONS: A pharmacy benefit design change from tiered copayment to tiered coinsurance, without a significant increase in beneficiary 00P costs, was associated with a lower rate of increase in total pharmacy benefit cost and no significant reduction in utilization. For utilizers in 3 essential drug classes, drug utilization and total spending increased in the coinsurance group but at a lower rate of increase compared with the copayment group. The coinsurance design provides another approach for controlling prescription utilization and spending for certain medication classes.

\section{J Manag Care Pharm. 2007;13(9):765-77}

Copyright@ 2007, Academy of Managed Care Pharmacy. All rights reserved.

\section{What is already known about this subject}

- Previous research on the effect of coinsurance has yielded mixed results and has been limited to only a few services and select populations; e.g., elderly, lower income, or patients for whom out-of-pocket cost was very low before coinsurance implementation.

- The effect on prescription drug utilization of changing from a tiered copayment to a tiered coinsurance structure has not been examined.

\section{What this study adds}

- Following implementation of a $25 \%$ coinsurance structure (and 50\% for non-preferred tier-3 drugs) with minimum and maximum out-of-pocket costs for each of 4 tiers, total prescription drug spending increased by $6.3 \%$, compared with a $9.5 \%$ increase for a comparison plan that retained a 3-tier copayment structure $(P=0.013)$.

- The switch from 3-tier copayment to coinsurance was associated with a $2.4 \%$ increase in per member utilization that was not different from the $4.6 \%$ increase in utilization in the comparison group $(P=0.189)$, and the $7.5 \%$ increase in beneficiary cost in the coinsurance group was not different from the $3.0 \%$ increase in the comparison group $(P=0.983)$. 
- For patients who used drugs in 3 essential drug classes (antihypertensives, antidepressants, and statins) in the pre-change and post-change periods, total pharmacy benefit cost increased by $8.2 \%$ in the coinsurance group and $13.3 \%$ in the comparison group, a difference of $\$ 2.73$ per patient per month $(P=0.003)$. The increase in utilization for the 3 essential drug classes was lower in the intervention group (4.1\%) than in the comparison group (9.0\%, $P=0.004)$.

I ncreased spending on prescription drugs is a growing concern for employers, patients, and payers. According to the Centers for Medicare \& Medicaid Services, drug spending has moderated in recent years by increasing $5.8 \%$ in 2005 after rising $14.3 \%$ from 2000 to $2002,10.2 \%$ in 2003 , and $8.6 \%$ in 2004. ${ }^{1,2}$ The rise in spending is driven by an influx of new, expensive medications, drug price inflation, and increased utilization of prescription drugs. Of these factors, increased utilization may be most easily influenced by health plans and pharmacy benefit managers. ${ }^{3}$

Patient cost-sharing through a copayment or coinsurance is one common technique for influencing patient utilization of medications. Previous research in this area has shown that increasing patient cost-share decreases medication use. ${ }^{4-21}$ However, only a few of these studies utilized strong research designs, such as a pre-post intervention design with a comparator group. ${ }^{6-8,14,16,17,19}$ Also, few studies examine the changes seen in larger cost-sharing differences in an adult, commercial insurance population. ${ }^{8,14}$

The challenge when increasing patient cost-share is to ensure that patients do not forgo valuable treatments as a result of the greater cost-share. Research has shown that 2-tier benefit designs, used to influence the choice of treatment in favor of lower-cost generic medications, decreased drug expenditures and utilization over single-tier programs but still did not differentiate between more and less valuable brand name treatments. ${ }^{22}$ Studies examining further differentiation have shown that moving from a 2-tier (generic and brand) to a 3-tier (generic, preferred brand, non-preferred brand) copayment system decreases the use of non-preferred brand medications and increases the use of preferred brand medications and generic medications. ${ }^{3,8,14,23-28}$

Most pharmacy benefit design studies to date have examined the relationship between changes to flat copayments and utilization of medications. Coinsurance benefits are becoming more widely used, and there is little information about the effect that a transition from fixed-dollar copayments to coinsurance has on prescription drug utilization. Coinsurance reflects differences in the costs of the medications to further differentiate products within each tier. In addition, the cost paid by the consumer adjusts as drug prices increase, stabilizing the cost-share mix between the consumer and payer over time.
Research on coinsurance is limited and has yielded mixed results. Studies were conducted following a cost-sharing change from $\$ 0$ or $\$ 2$ copayments per prescription to $25 \%$ coinsurance (including monthly and annual maximum out-of-pocket [OOP] expense) implemented in Quebec, Canada. Investigators found that utilization in certain drug classes remained unchanged, ${ }^{13,29,30}$ while utilization decreased in others. ${ }^{13,15}$ However, these studies are limited in their relevance to more recent cost-sharing changes, where baseline patient expenditures are usually higher. Some studies have compared the effects of increased copayments and increased coinsurance rates on drug utilization and medical care utilization in elderly populations in the United States and have found a decrease in expenditures and utilization with no subsequent change in medical expenses. ${ }^{16,17}$

More recent research into coinsurance has examined the effect of coinsurance on self-monitoring of blood glucose by diabetic patients and on adherence rates to beta-blocker therapy. ${ }^{31,32}$ In the study of diabetic patients, daily utilization of glucose monitoring test strips declined after the plan switched from no member cost-sharing to coinsurance, but the amount of change was not clinically significant. ${ }^{31}$ The beta-blocker study examined the effect of OOP cost-sharing changes, first from $\$ 0$ to $\$ 10$ or $\$ 25$ copayment and then to $25 \%$ coinsurance. Cost-sharing changes were associated with minimal (approximately $1 \%$ ) declines in the beta-blocker adherence rate (percentage of patients with medication possession ratio $>80 \%$ ) for patients with hypertension and no significant change in the rate of initiation of beta-blocker therapy following a myocardial infarction. ${ }^{32}$ Earlier coinsurance research was conducted before the development of expensive biologic medications and the introduction of generic drugs in several blockbuster drug classes.

To date, no studies have examined the effect of changing from a tiered copayment design to a tiered coinsurance design. With little evidence on the effect that this type of change will have on patient behavior and costs, we examined such a design change and its effects on expenditures and utilization. By using a comparison group to adjust for utilization and cost trends in a plan with a copayment design, this study was able to estimate the impact of the benefit design change on medication utilization and expenditures. Utilization was analyzed both overall (for all therapeutic classes combined) and for 3 chronic medication classes: antihypertensives, antidepressants, and statins.

\section{Methods}

\section{Study Population}

This retrospective cohort study analyzed enrollment and pharmacy claims data maintained by a managed care organization in a midwestern state from September 1, 2004, through March 31, 2006. It was approved by the institutional review board at the University of Nebraska Medical Center. The study used a pre-post analysis of an intervention group evaluated against a comparison group. Both the intervention 
and comparison cohorts represented large privately insured preferred provider organization groups. Both cohorts employed an identical 3-tier copayment pharmacy benefit plan design (generic, formulary brand, non-formulary brand) during the pre-implementation period. On September 1, 2005, the intervention group changed from the 3-tier copayment design to a 4-tier coinsurance design due to an employer group decision. Table 1 shows the groups' benefit during each period of analysis. A 4th cost-share tier (25\%) was created in the intervention group for specialty pharmaceuticals, including injectable medications, which were tier-2 or tier-3 copayment medications during the pre-change period and remained in these copayment tiers for the comparison group throughout the study period. A separate study evaluating the effect of the benefit change on those medications is underway. ${ }^{33}$ The formulary and tier status for all other medications (Table 2) was consistent between the 2 study groups.

Both plans offered an optional mail order benefit. Member cost-share at mail for a 6-month supply (151 to 180 days supply) was equivalent to 5 copayments for that tier for the comparison group and the corresponding coinsurance rate for the respective tier for the intervention group with minimum/maximum values 5 times the 1-month supply values. For example, a generic medication filled at mail order for a 180 days supply in the intervention group would be subject to $25 \%$ coinsurance with a minimum of $\$ 25$ (5 times the tier-1 minimum of $\$ 5$ ) and a maximum of $\$ 125$ (5 times the tier-1 maximum of $\$ 25$ ). Claims processed at community pharmacies could be filled only for 3-month supplies or less. Mail order utilization rates for the intervention and comparison groups during the entire study period were $0.84 \%$ and $0.11 \%$ of claims, respectively.

An important feature of the coinsurance design was the inclusion of minimum and maximum patient cost-sharing levels. The minimum value was included to maintain the cost-share differences between tiers and the maximum was included to insulate the member from the cost of relatively expensive medications. Patients in the intervention group could see a reduction in their spending on tier-1 medications because the $\$ 5$ minimum was below their previous $\$ 10$ copayment. For tier- 2 medications, any change in patient cost-share was related to medication price because the minimum was equal to the $\$ 25$ copayment. Users of tier-3 medications, however, faced a minimum increase of $\$ 10$ because the minimum ( $\$ 50)$ was greater than the previous copayment.

To be included in the present study, beneficiaries had to be continuously enrolled for the entire 19-month study period (12 months before the plan change and 7 months after the plan change) and be $\geq 18$ years of age at the beginning of the study period. All beneficiaries meeting the continuous enrollment criteria were included in analyses of overall (all drugs) utilization and cost. To be included in the analyses of the 3 essential medication classes (antihypertensives, antidepressants, and statins), an
TABLE 1 Pharmacy Benefit Designs

\begin{tabular}{|c|c|c|c|c|}
\hline \multicolumn{2}{|c|}{ Comparison } & \multirow[b]{3}{*}{ Copayment Tier ${ }^{\dagger}$} & \multicolumn{2}{|c|}{ Intervention } \\
\hline Copay (\$) & Copay (\$) & & Copay (\$) & Coinsurance* \\
\hline $\begin{array}{c}\text { Pre- } \\
\text { change }\end{array}$ & $\begin{array}{l}\text { Post- } \\
\text { change }\end{array}$ & & $\begin{array}{c}\text { Pre- } \\
\text { change }\end{array}$ & $\begin{array}{l}\text { Post- } \\
\text { change }\end{array}$ \\
\hline \multirow[t]{2}{*}{10} & 10 & 1 & 10 & $25 \%$ \\
\hline & & $($ Min-Max $) \ddagger$ & & $(\$ 5-\$ 25)$ \\
\hline \multirow[t]{2}{*}{25} & 25 & 2 & 25 & $25 \%$ \\
\hline & & (Min-Max) & & $(\$ 25-\$ 50)$ \\
\hline \multirow[t]{2}{*}{40} & 40 & 3 & 40 & $50 \%$ \\
\hline & & (Min-Max) & & $(\$ 50-\$ 75)$ \\
\hline \multirow[t]{4}{*}{ N/A } & N/A & 4 & N/A & $25 \%$ \\
\hline & & (Min-Max) & & $(\$ 50-\$ 100)$ \\
\hline & & Out-Net§ & & $50 \%$ \\
\hline & & (Min-Max) & & $(\$ 150-\$ 300)$ \\
\hline
\end{tabular}

Out-of-Pocket Maximum (per Calendar Year ${ }^{\|}$)

\begin{tabular}{|c|c|c|c|}
\hline \multirow[t]{2}{*}{ None } & \multirow[t]{2}{*}{ None } & \multirow{2}{*}{$\begin{array}{l}9 / 1 / 2004-12 / 31 / 2004 \\
1 / 1 / 2005-12 / 31 / 2005\end{array}$} & $\$ 2,000 /$ individual \\
\hline & & & $\$ 4,000 /$ family \\
\hline \multirow[t]{2}{*}{ None } & None & \multirow{2}{*}{$1 / 1 / 2006-12 / 31 / 2006$} & $\$ 2,500 /$ individual \\
\hline & & & $\$ 5,000 /$ family \\
\hline
\end{tabular}

The copayment and coinsurance rates correspond to a 1-month supply of medication. The pre-change refers to the 12 months preceding the benefit change and the post-change refers to the 7 months after the benefit change. Member cost-share at mail for a 6-month supply (151 to 180 days supply) was equivalent to 5 copayments for that tier or 5 times the minimum/maximum values with the corresponding coinsurance rate for the respective tier. For example, a tier-1 medication filled at mail order for a 180 days supply in the intervention group would be subject to $25 \%$ coinsurance with a minimum of $\$ 25$ and a maximum of $\$ 125$.

* The coinsurance percentage is the percentage of the contracted price for the medication in the quantity dispensed.

$\dagger$ Generic drugs (tier 1), preferred brand drugs (tier 2), non-preferred brand drugs (tier 3), specialty/biologic drugs (tier 4). Specialty pharmacy drugs, including injectable biologics, were covered in the pharmacy benefit for both groups throughout the study period.

$\mp$ The minimum and maximum out-of-pocket cost for that cost-share tier. For the minimum amount, the member pays the greater of the $25 \%$ cost-share or the minimum dollar amount up to the allowable charge; i.e., the member does not pay more OOP than the allowable charge.

$\S$ Out-of-network providers (Out-Net) of specialty medications are subject to higher out-of-pocket expenses than are those that are contracted as in-network providers that are subject to lower coinsurance rates.

|| Calendar year is from January 1 to December 31. The member's or family's out-of-pocket cost is reset to zero on January 1 of each year even though the plan year is from September 1 to August 31 and benefit design changes generally take effect on September 1. 


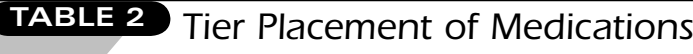

\begin{tabular}{l|l|l}
\hline \multicolumn{3}{c}{ Antihypertensives } \\
$\begin{array}{l}\text { Generics } \\
\text { (Tier 1)* }\end{array}$ & \multicolumn{1}{c}{$\begin{array}{c}\text { Preferred Brand } \\
\text { (Tier 2) }\end{array}$} & $\begin{array}{c}\text { Non-Preferred Brand } \\
\text { (Tier 3) }\end{array}$ \\
\hline Atenolol & Altace & Accupril $\dagger$ \\
\hline Atenolol/Chlorthalidone & Coreg & Accuretic $¥$ \\
\hline Benazepril & Cozaar & Atacand \\
\hline Benazepril/HCTZ & Dibenzyline & Atacand HCT \\
\hline Bisoprolol & Diamox & Avalide \\
\hline Bisoprolol/HCTZ & Diovan & Avapro \\
\hline Captopril & Diovan HCT & Benicar \\
\hline Cartia XT & Hyzaar & Benicar HCT \\
\hline Clonidine & Lotrel & Cardizem LA \\
\hline Diltiazem & NorvasC & Inderal LA \\
\hline Diltiazem ER & Toprol XL & Mavik \\
\hline Enalapril & & Micardis \\
\hline Enalapril/HCTZ & & Micardis HCT \\
\hline Fosinopril & & Tarka \\
\hline Furosemide & & Univasc \\
\hline HCTZ & & \\
\hline Lisinopril & & \\
\hline Lisinopril/HCTZ & & \\
\hline Metoprolol & & \\
\hline Nadolol & & \\
\hline Nifedical XL & & \\
\hline Nifedipine ER & & \\
\hline Propranolol & & \\
\hline Spironolactone & & \\
\hline Spironolactone/HCTZ & & \\
\hline Taztia XT & & \\
\hline Torsemide & & \\
\hline Triamterene/HCTZ & & \\
\hline Verapamil CR & & \\
\hline Verapamil ER & & \\
\hline & & \\
\hline
\end{tabular}

\begin{tabular}{l|l|l}
\hline $\begin{array}{c}\text { Generics } \\
\text { (Tier 1) }\end{array}$ & \multicolumn{1}{|c|}{$\begin{array}{c}\text { Preferred Brand } \\
\text { (Tier 2) }\end{array}$} & $\begin{array}{c}\text { Non-Preferred Brand } \\
\text { (Tier 3) }\end{array}$ \\
\hline Citalopram & Effexor & Celexa $\dagger$ \\
\hline Fluoxetine & Effexor XR & Cymbalta \\
\hline Fluvoxamine & Paxil CR & Paxil \\
\hline Paroxetine & Zoloft & Prozac \\
\hline & & Prozac Weekly \\
\hline & & Sarafem \\
\hline & & Lexapro \\
\hline
\end{tabular}

Statins

\begin{tabular}{l|l|l}
\hline $\begin{array}{c}\text { Generics } \\
\text { (Tier 1) }\end{array}$ & \multicolumn{1}{|c|}{$\begin{array}{c}\text { Preferred Brand } \\
\text { (Tier 2) }\end{array}$} & \multicolumn{1}{c}{$\begin{array}{c}\text { Non-Preferred Brand } \\
\text { (Tier 3) }\end{array}$} \\
\hline Lovastatin & Lipitor & Crestor \\
\hline & Zocor & Advicor \\
\hline & Vytorin§ & Altoprev \\
\hline & & Pravachol \\
\hline & & Lescol \\
\hline & & Lescol XL \\
\hline
\end{tabular}

* All generic antihypertensives have tier-1 cost share.

$\dagger$ Moved from cost-share tier 2 to tier 3 on January 1, 2005.

\# Moved from cost-share tier 2 to tier 3 on October 1, 2004.

$\S$ Moved from cost-share tier 3 to tier 2 on January 1, 2005.

SNRI=serotonin/norepinephrine reuptake inhibitor; SSRI=selective serotonin reuptake inhibitor. enrollee had to have at least 1 pharmacy claim for a medication in the therapeutic class in each of 2 periods: the pre-change (October 1, 2004, to March 31, 2005) and the post-change (October 1, 2005, to March 31, 2006). The Figure shows the sample development.

\section{Definition of Essential Drug Classes}

Drug classes for the analyses of essential medications were limited to chronic medications previously defined as "essential," subject to prior authorization programs, and were not typically dispensed "as needed." The medication classes were (1) antihypertensives identified by Medi-Span Generic Product Identifier (GPI) codes beginning with 33 (beta-blockers), 34 (calcium channel blockers), 36 (angiotensin-converting enzyme inhibitors, angiotensin II receptor blockers, adrenolytic antihypertensives), and 37 (diuretics); (2) antidepressants, which were limited to selective serotonin reuptake inhibitors (SSRIs) and serotonin/norepinephrine reuptake inhibitors (SNRIs) identified by GPI codes beginning with 5816, 5818, and 58300090; and (3) HMG-CoA reductase inhibitors (statins) and statin combination products identified by GPI codes beginning with 3940 and 3999.

\section{Utilization and Expenditures}

Utilization included both community and mail order pharmacy claims. Employer cost was defined as the amount paid by the plan sponsor; beneficiary cost was the amount paid by the patient; and total cost was the sum of the discounted ingredient cost plus the dispensing fee to the pharmacy. Pharmacy claim counts were adjusted for days supply (i.e., 90 days supply $=3$ claims).

The analyses examined (1) utilization and cost overall (i.e., for all therapeutic classes), and (2) participation rates, utilization, and cost for the 3 essential medication classes. For the analyses of overall utilization, totals (pharmacy claims counts, member OOP costs, employer costs, and total costs) for each of the 2 study periods were divided by the total number of enrollment months (6 months for each member because the study sample was limited to continuously eligible members) to yield per member per month (PMPM) values. Participation rates for each of the 2 periods were calculated as the percentage of members with a claim for each of the 3 essential medication classes.

For each of the 3 essential medication classes, the utilization measure was total days supply dispensed, and cost measures included member OOP, employer cost, and total cost. For the analyses of these 3 classes, dividing totals by the number of enrollment months ( 6 months in each period) yielded per patient per month (PPPM) values because these analyses included only members with utilization in the therapeutic class in both study periods.

\section{Statistical Analysis}

For the statistical analyses of utilization and cost, two 6 -month cohorts were constructed for the intervention and 


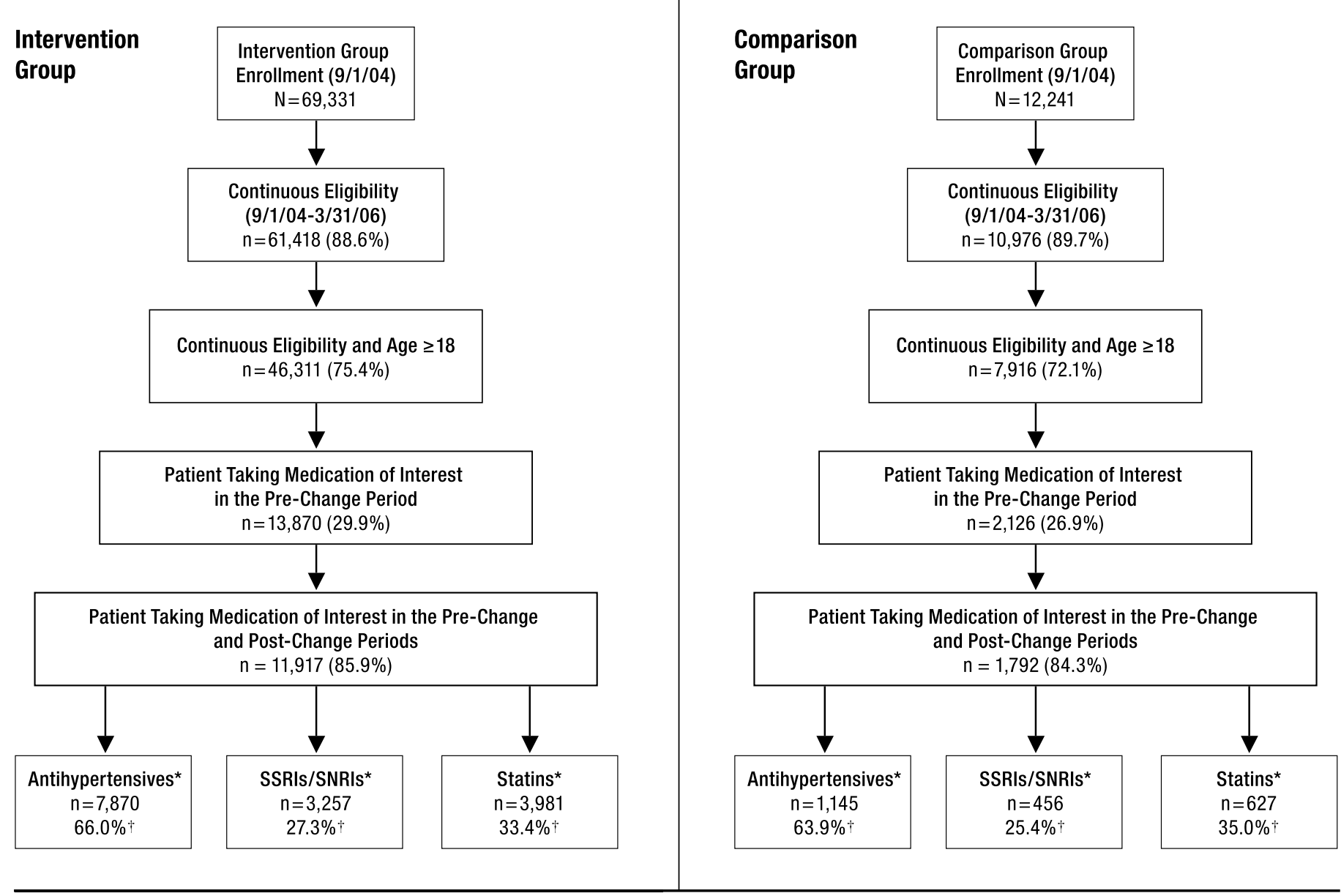

* Antihypertensives, SSRIs/SNRIs, and statins are identified by GPI number.

$\dagger$ Percentages do not total $100 \%$ because patients may be taking medications in multiple classes.

Pre-change period=October 1, 2004, through March 31, 2005; post-change period=October 1, 2005, through March 31, 2006.

GPI=Generic Product Identifier; SNRI=serotonin/norepinephrine reuptake nhibitor; SSRI=selective serotonin reuptake inhibitor.

comparison groups. The 6-month time periods were October 1 , 2004, to March 31, 2005, and October 1, 2005, to March 31, 2006, to account for any seasonality that might affect utilization. The first month after the benefit change was excluded to account for hoarding in the intervention group during August previous to the benefit change that would have skewed September 2005 utilization in the intervention group. Changes in utilization and expenditures between the prechange and post-change periods for both groups were calculated. A difference-in-difference (DD) analysis was utilized to determine the difference in the change (pre- to post-) between the intervention and comparison groups. The DD analysis is the most appropriate measure of the effect of the design change because it controls for the utilization (expenditure) changes that would have occurred over time and also for differences between the intervention and comparison groups in utilization. The Wilcoxon rank sum test (also known as the Mann-Whitney $U$ test) was used to analyze the difference in the change between the 2 groups.

Two-tailed $t$ tests were used to determine the significance in difference in age between the 2 groups and $\chi^{2}$ analyses were used to calculate the difference in gender between the 2 groups and the participation rates for the 3 medication classes included in this study. The Wilcoxon rank sum test was used to analyze the difference in Chronic Disease Scores ${ }^{34}$ between the 2 groups. The significance level for all statistical analyses was set at $P \leq 0.05$. All cohorts were grouped and statistical analyses were conducted with SAS Version 8.0 (SAS Institute Inc., Cary, NC). 


\begin{tabular}{|c|c|c|c|c|c|c|c|c|c|c|}
\hline & \multicolumn{4}{|c|}{$\begin{array}{c}\text { Intervention } \\
(\mathrm{n}=46,311)\end{array}$} & \multicolumn{4}{|c|}{$\begin{array}{c}\text { Comparison } \\
(\mathrm{n}=7,916)\end{array}$} & \multirow[t]{2}{*}{$\mathrm{DD}^{\dagger}$} & \multirow[t]{2}{*}{$\begin{array}{c}\text { Wilcoxon } \S \\
P \text { Value }\end{array}$} \\
\hline & Pre & Post & Change & $\%$ & Pre & Post & Change & $\%$ & & \\
\hline Rx utilization & 1.26 & 1.29 & 0.03 & 2.4 & 1.08 & 1.13 & 0.05 & 4.6 & -0.22 & 0.189 \\
\hline Patient OOP (\$)丰 & 22.76 & 24.47 & 1.71 & 7.5 & 20.61 & 21.22 & 0.62 & 3.0 & 1.10 & 0.983 \\
\hline Employer (\$) & 49.53 & 52.40 & 2.88 & 5.8 & 40.93 & 46.19 & 5.26 & 12.9 & -2.38 & 0.077 \\
\hline Total (\$) & 72.29 & 76.87 & 4.57 & 6.3 & 61.54 & 67.41 & 5.87 & 9.5 & -1.30 & 0.013 \\
\hline
\end{tabular}

* Pre-change period=October 1, 2004, through March 31, 2005; post-change period=October 1, 2005, through March 31, 2006.

$\dagger$ Discrepancies in the difference-in-difference calculation are due to rounding.

₹ The post-change patient OOP cost-share was 31.8\% (24.47/76.87)) for the intervention group versus 31.5\% (21.22/67.41) for the comparison group. The generic dispensing ratios for the pre-change and post-change periods were $47.5 \%$ and $51.4 \%$, respectively, for the intervention group and $48.2 \%$ and $50.2 \%$, respectively, for the comparison group.

$\S$ The Wilcoxon rank sum test was used to compare the intervention and comparison groups. Percentages refer to the percentage change from the pre-change to the postchange period. Utilization is number of claims adjusted for days supply (i.e., 90 days supply $=3$ claims).

$D D=$ the difference-in-difference estimate; $O O P=$ out-of-pocket; $P M P M=$ per member per month.

\begin{tabular}{l|c|c|c|c}
\hline (TABLE 4 & Participation Rates* \\
\hline & Study Period & $\begin{array}{c}\text { Intervention } \\
\mathrm{n}=46,311\end{array}$ & $\begin{array}{c}\text { Comparison } \\
\mathrm{n}=7,916\end{array}$ & $P$ Value \\
\hline Antihypertensives & & & & \\
\hline & Pre (\%) & $8,856(19.1)$ & $1,306(16.5)$ & $<0.001$ \\
\hline & Post (\%) & $10,180(22.0)$ & $1,562(19.7)$ & $<0.001$ \\
\hline & Change (\%) & $1,324(2.9)$ & $256(3.2)$ & 0.444 \\
\hline & & & & \\
\hline SSRIs/SNRIs & Pre (\%) & $4,578(9.9)$ & $676(8.5)$ & $<0.001$ \\
\hline & Post (\%) & $5,178(11.2)$ & $776(9.8)$ & $<0.001$ \\
\hline & Change (\%) & $600(1.3)$ & $100(1.3)$ & 0.721 \\
\hline & & & & \\
\hline & Pre (\%) & $4,820(10.4)$ & $739(9.3)$ & 0.004 \\
\hline & Post (\%) & $5,634(12.2)$ & $926(11.7)$ & 0.246 \\
\hline & Change (\%) & $814(1.8)$ & $187(2.4)$ & 0.072 \\
\hline
\end{tabular}

* The number (\%) of beneficiaries in a group with a claim for a medication in the class in each period.

Differences between the intervention and comparison groups were determined using Pearson $\chi^{2}$ analyses.

Pre-change period=October 1, 2004, through March 31, 2005; post-change period=October 1, 2005, through March 31, 2006.

$S N R I=$ indicates serotonin/norepinephrine reuptake inhibitor; SSRI=selective serotonin reuptake inhibitor.

\section{Results}

\section{Overall Utilization}

A total of 46,311 and 7,916 members aged $\geq 18$ years were continuously enrolled during the study period in the intervention and comparison groups, respectively. Changes in PMPM utilization and cost for the 2 groups are presented in Table 3. In the post-change period, intervention group beneficiaries paid $31.8 \%$ of total prescription drug cost versus $31.5 \%$ for comparison group beneficiaries. The increases in beneficiary cost from the pre-change to the post-change period were not significantly different for the intervention (7.5\%) and comparison $(3.0 \%)$ groups $(P=0.983)$. From the pre-change to the post-change period, total spending per member increased
$\$ 4.57$ PMPM (6.3\%), from $\$ 72.29$ to $\$ 76.87$, in the intervention group versus a $\$ 5.87$ PMPM increase (9.5\%), from $\$ 61.54$ to $\$ 67.41$, in the comparison group, a relative difference of $\$ 1.30$ PMPM $(P=0.013)$. The increases in utilization from the pre-change to the post-change period were not significantly different in the intervention group (2.4\%) versus the comparison group $(4.6 \%, P=0.189)$.

\section{Participation Rates for 3 Essential Drug Classes}

Of the 46,311 and 7,916 study members in the intervention and comparison groups, respectively, 13,870 (29.9\% of the intervention group) and 2,126 (26.9\% of the comparison group) filled at least 1 prescription for a medication in 1 of the 3 study drug classes in the pre-change period. For all 3 classes, participation was higher in the intervention group than in the comparison group in both the pre-change and post-change periods (Table 4). Participation rates increased slightly from the pre-change to the post-change period in both groups. While the increases were slightly greater in the comparison group than in the intervention group for all 3 classes, the differences in the change amounts were not statistically significant.

\section{Utilizers of 3 Essential Drug Classes}

A total of 11,917 members in the intervention group and 1,792 members in the comparison group filled at least 1 prescription for at least 1 of the 3 essential medication classes in both the pre-change and post-change periods. Among users of the 3 essential medication classes, the intervention group was significantly older and sicker than the comparison group. Except in the antidepressant class, the intervention group had a significantly higher percentage of women filling prescriptions than did the comparison group (Table 5). While these differences are statistically significant due to the large sample 
size, they are probably not practically or clinically significant. Women were generally the predominant gender in all drug classes in both the intervention and comparison groups with the exception of the statins drug class, where more than half the patients were men.

Table 6a shows utilization and expenditures for patients in the 2 study groups in the pre-change and post-change periods. Total PPPM days supply summed across the 3 drug classes increased from the pre-change to the post-change period for both the intervention and comparison groups, from 38.99 to 40.58 (4.1\%) for the intervention group and from 35.78 to 39.01 (9.0\%) for the comparison group. The change amount was slightly smaller for the intervention group (1.59 days PPPM) than for the comparison group ( 3.23 days PPPM, $P=0.004)$. From the pre-change to the post-change period, mean PPPM OOP spending increased by $\$ 2.20$ and $\$ 2.12$ for the intervention and comparison groups, respectively, a difference of $\$ 0.08$ per month $(P=0.032)$. The increases in employer cost in the intervention group (7.5\%, $\$ 2.86$ PPPM) and comparison group (16.1\%, \$5.67 PPPM) did not significantly differ $(P=0.057)$. The PPPM changes in the total cost of prescription drugs were $\$ 5.07$ (8.2\%) and $\$ 7.80$ (13.3\%) in the intervention and comparison groups, respectively, a difference of $\$ 2.73$ PPPM $(P=0.003)$. The 2 groups did not significantly differ with respect to change in utilization of tier-1 or tier-2 drugs. For tier-3 drugs, utilization remained essentially constant from the pre-change to the post-change period in the intervention group (change of 0.09 days PPPM) but increased slightly in the comparison group (change of 0.43 days PPPM, $P=0.002$ ).

From the pre-change to the post-change period, patient OOP cost for tier- 1 medications decreased by $\$ 0.85$ PPPM in the intervention group and increased by $\$ 0.43$ PPPM in the comparison group $(P<0.001)$. The decrease in patient OOP for the intervention group was offset by an increase in the employer group's expenditures. The increase in employer group expenditures of \$1.33 PPPM in the intervention group was significantly higher than the $\$ 0.29$ increase observed in the comparison group $(P<0.001)$. As a result, the intervention and comparison groups did not significantly differ with respect to change in total spending on tier-1 medications.

With respect to patient OOP spending, results for tier-2 medications were the opposite of the tier-1 results. PPPM OOP spending increased $\$ 0.27$ more in the intervention group than in the comparison group $(P<0.001)$, while PPPM employer group spending increased by $\$ 1.43$ less in the intervention group than in the comparison group $(P=0.017)$. As with the tier-1 medications, the 2 study groups did not significantly differ with respect to change in total tier- 2 cost $(P=0.150)$.

PPPM OOP expenditures on tier-3 medications increased by $\$ 1.09$ more in the intervention group than in the comparison group $(P<0.001)$. Employer group spending on tier-3 medications decreased by $\$ 0.77$ PPPM in the intervention group while it increased by $\$ 1.65$ PPPM in the comparison group $(P<0.001)$.

\begin{tabular}{|c|c|c|c|}
\hline & Intervention & Comparison & $P$ Value \\
\hline Total for all 3 drug classes & $\mathrm{n}=11,917$ & $\mathrm{n}=1,792$ & \\
\hline Age in years, mean [SD] & $52.8[10.2]$ & $52.2[11.3]$ & 0.019 \\
\hline Males, no. (\%) & $4,873(40.9)$ & $830(46.3)$ & $<0.001$ \\
\hline CDS, mean [SD] & $2.60[2.5]$ & $2.33[2.6]$ & $<0.001$ \\
\hline Antihypertensives & $\mathrm{n}=7,870$ & $\mathrm{n}=1,145$ & \\
\hline Age in years, mean [SD] & $54.8[8.7]$ & $54.3[10.1]$ & 0.135 \\
\hline Males, no. (\%) & $3,452(43.9)$ & $560(48.9)$ & 0.001 \\
\hline $\mathrm{CDS}$, mean $[\mathrm{SD}]$ & $2.60[2.5]$ & $2.33[2.6]$ & $<0.001$ \\
\hline SSRIs/SNRIs & $\mathrm{n}=3,257$ & $\mathrm{n}=456$ & \\
\hline Age in years, mean [SD] & $47.3[12.3]$ & $46.1[12.7]$ & 0.054 \\
\hline Males, no. (\%) & $695(21.3)$ & $106(23.3)$ & 0.354 \\
\hline CDS, mean [SD] & $2.55[2.5]$ & $2.21[2.4]$ & 0.004 \\
\hline Statins & $\mathrm{n}=3,981$ & $\mathrm{n}=627$ & \\
\hline Age in years, mean [SD] & $56.1[7.2]$ & $55.6[8.7]$ & 0.173 \\
\hline Males, no. (\%) & $2,218(55.7)$ & $389(62.0)$ & 0.003 \\
\hline CDS, mean [SD] & $2.60[2.6]$ & $2.47[2.7]$ & 0.063 \\
\hline \multicolumn{4}{|c|}{$\begin{array}{l}\text { Age comparison between the groups was determined using 2-tailed t tests and } \\
\text { gender differences were determined using Pearson } \chi^{2} \text { analyses. } \\
C D S=\text { Chronic Disease Score }{ }^{34} ; \text { SNRI=indicates serotonin/norepinephrine } \\
\text { reuptake inhibitor; SSRI= selective serotonin reuptake inhibitor. }\end{array}$} \\
\hline
\end{tabular}

As a result, overall spending on tier-3 medications increased by $\$ 1.33$ more PPPM in the comparison group than in the intervention group.

\section{Medication Class Utilization and Expenditures}

Tables $6 \mathrm{~b}-6 \mathrm{~d}$ show the differences in utilization and expenditures for the 3 classes of medications. Overall utilization increased in both study groups for the 3 classes evaluated. The increase in utilization was significantly less for the intervention group than for the comparison group in each class. No significant differences in total utilization or cost for tier-1 or tier-2 medications were observed in any class; only utilization of tier-3 antihypertensives $(P=0.031)$ and tier-3 statins $(P=0.029)$ differed significantly from the comparison group.

The effect of the benefit change on OOP spending varied depending on class and tier. Overall OOP expenditure increased $\$ 1.54$ PPPM less in the intervention group than in the comparison group for antihypertensives $(P<0.001)$, while it increased $\$ 1.90$ more in the intervention group than in the comparison group for statins $(P<0.001)$. For tier-1 antihypertensives and SSRIs/ SNRIs, OOP spending in the intervention group decreased by $\$ 1.32$ PPPM and \$0.07 PPPM, respectively, from the pre-change period to the post-change period. Conversely, OOP spending for tier-3 medications increased significantly more in the intervention group than in the comparison group for all 3 classes. 
Effect on Drug Utilization and Expenditures of a

Cost-Share Change From Copayment to Coinsurance

\section{TABLE 6 Mean PPPM Change from Pre-Change Period to Post-Change Period*}

\section{6a. All 3 Drug Classes}

\begin{tabular}{|c|c|c|c|c|c|c|c|c|c|c|}
\hline \multirow[b]{2}{*}{ All Tiers } & \multicolumn{4}{|c|}{$\begin{array}{c}\text { Intervention } \\
(\mathrm{n}=11,917)\end{array}$} & \multicolumn{4}{|c|}{$\begin{array}{c}\begin{array}{c}\text { Comparison } \\
\mathrm{n}=1,792\end{array} \\
\end{array}$} & \multirow[t]{2}{*}{ DD } & \multirow[t]{2}{*}{$\begin{array}{c}\text { Wilcoxon } \dagger \\
P \text { Value } \\
\end{array}$} \\
\hline & Pre & Post & Change & $\%$ & Pre & Post & Change & $\%$ & & \\
\hline Utilization (days) & 38.99 & 40.58 & 1.59 & 4.1 & 35.78 & 39.01 & 3.23 & 9.0 & -1.63 & 0.004 \\
\hline Patient OOP (\$) & 23.98 & 26.18 & 2.20 & 9.2 & 23.22 & 25.34 & 2.12 & 9.1 & 0.08 & 0.032 \\
\hline Employer (\$) & 38.04 & 40.91 & 2.86 & 7.5 & 35.18 & 40.85 & 5.67 & 16.1 & -2.81 & 0.057 \\
\hline Total (\$) & 62.11 & 67.18 & 5.07 & 8.2 & 58.50 & 66.30 & 7.80 & 13.3 & -2.73 & 0.003 \\
\hline
\end{tabular}

Tier 1

\begin{tabular}{l|r|r|r|r|r|r|r|r|r|r}
\hline Utilization (days) & 17.04 & 17.91 & 0.86 & 5.0 & 15.44 & 17.02 & 1.57 & 10.2 & -0.71 & 0.227 \\
\hline Patient OOP (\$) & 4.26 & 3.41 & -0.85 & -19.9 & 4.13 & 4.56 & 0.43 & 10.4 & -1.28 & $<0.001$ \\
\hline Employer (\$) & 4.46 & 5.79 & 1.33 & 29.9 & 4.50 & 4.79 & 0.29 & 6.4 & 1.04 & $<0.001$ \\
\hline Total (\$) & 8.73 & 9.21 & 0.48 & 5.5 & 8.66 & 9.37 & 0.72 & 8.3 & -0.23 & 0.868 \\
\hline
\end{tabular}

Tier 2

\begin{tabular}{l|r|r|r|r|r|r|r|r|r|r}
\hline Utilization (days) & 16.91 & 17.56 & 0.64 & 3.8 & 15.45 & 16.68 & 1.23 & 8.0 & -0.59 & 0.240 \\
\hline Patient OOP (\$) & 13.58 & 14.89 & 1.31 & 9.7 & 12.83 & 13.87 & 1.04 & 8.1 & 0.27 & $<0.001$ \\
\hline Employer (\$) & 28.49 & 30.79 & 2.30 & 8.1 & 25.87 & 29.61 & 3.74 & 14.4 & -1.43 & 0.017 \\
\hline Total (\$) & 42.06 & 45.58 & 3.61 & 8.6 & 38.71 & 43.48 & 4.78 & 12.3 & -1.15 & 0.150 \\
\hline
\end{tabular}

Tier 3

\begin{tabular}{l|r|r|r|r|r|r|r|r|r|r}
\hline Utilization (days) & 5.03 & 5.12 & 0.09 & 1.8 & 4.89 & 5.32 & 0.43 & 8.8 & -0.34 & 0.002 \\
\hline Patient OOP (\$) & 6.14 & 7.88 & 1.74 & 28.3 & 6.26 & 6.91 & 0.65 & 10.4 & 1.09 & $<0.001$ \\
\hline Employer (\$) & 5.09 & 4.32 & -0.77 & -15.2 & 4.80 & 6.45 & 1.65 & 34.3 & -2.42 & $<0.001$ \\
\hline Total (\$) & 11.32 & 12.29 & 0.98 & 8.6 & 11.14 & 13.45 & 2.31 & 20.7 & -1.33 & $<0.001$ \\
\hline
\end{tabular}

\section{6b. Antihypertensives}

\begin{tabular}{|c|c|c|c|c|c|c|c|c|c|c|}
\hline \multirow[b]{2}{*}{ All Tiers } & \multicolumn{4}{|c|}{$\begin{array}{c}\text { Intervention } \\
(\mathrm{n}=7,870)\end{array}$} & \multicolumn{4}{|c|}{$\begin{array}{c}\text { Comparison } \\
(\mathrm{n}=1,145)\end{array}$} & \multirow[t]{2}{*}{ DD } & \multirow[t]{2}{*}{$\begin{array}{c}\text { Wilcoxon } \dagger \\
P \text { Value } \\
\end{array}$} \\
\hline & Pre & Post & Change & $\%$ & Pre & Post & Change & $\%$ & & \\
\hline Utilization (days) & 35.69 & 36.95 & 1.26 & 3.5 & 33.15 & 35.94 & 2.79 & 8.4 & -1.54 & 0.017 \\
\hline Patient OOP (\$) & 17.86 & 17.88 & 0.02 & 0.1 & 17.38 & 18.94 & 1.56 & 9.0 & -1.54 & $<0.001$ \\
\hline Employer (\$) & 15.03 & 17.69 & 2.66 & 17.7 & 13.90 & 16.35 & 2.46 & 17.7 & 0.21 & $<0.001$ \\
\hline Total (\$) & 32.99 & 35.70 & 2.71 & 8.2 & 31.41 & 35.44 & 4.03 & 12.8 & -1.32 & 0.243 \\
\hline
\end{tabular}

Tier 1

\begin{tabular}{l|r|r|r|r|r|r|r|r|r|r}
\hline Utilization (days) & 21.25 & 22.09 & 0.84 & 4.0 & 19.72 & 21.37 & 1.65 & 8.4 & -0.81 & 0.233 \\
\hline Patient OOP (\$) & 4.99 & 3.67 & -1.32 & -26.5 & 4.93 & 5.30 & 0.37 & 7.5 & -1.69 & $<0.001$ \\
\hline Employer (\$) & 3.17 & 4.82 & 1.65 & 52.1 & 3.13 & 3.46 & 0.34 & 10.9 & 1.32 & $<0.001$ \\
\hline Total (\$) & 8.16 & 8.49 & 0.33 & 4.0 & 8.06 & 8.76 & 0.70 & 8.7 & -0.37 & 0.771 \\
\hline
\end{tabular}

Tier 2

\begin{tabular}{l|r|r|r|r|r|r|r|r|r|r}
\hline Utilization (days) & 10.86 & 11.19 & 0.33 & 3.0 & 10.02 & 10.86 & 0.83 & 8.3 & -0.50 & 0.358 \\
\hline Patient OOP (\$) & 8.67 & 9.03 & 0.36 & 4.2 & 8.29 & 9.01 & 0.72 & 8.7 & -0.37 & 0.752 \\
\hline Employer (\$) & 10.30 & 11.52 & 1.49 & 14.9 & 9.24 & 10.92 & 1.67 & 18.1 & -0.18 & 0.596 \\
\hline Total (\$) & 18.70 & 20.55 & 1.85 & 9.9 & 17.53 & 19.92 & 2.40 & 13.7 & -0.55 & 0.779 \\
\hline Tier 3 \\
\hline Utilization (days) & 3.59 & 3.67 & 0.08 & 2.2 & 3.41 & 3.72 & 0.31 & 9.1 & -0.23 & 0.031 \\
\hline Patient OOP (\$) & 4.20 & 5.19 & 0.99 & 23.6 & 4.17 & 4.64 & 0.47 & 11.3 & 0.52 & 0.002 \\
\hline Employer (\$) & 1.83 & 1.36 & -0.48 & -26.2 & 1.53 & 1.98 & 0.45 & 29.4 & -0.93 & $<0.001$ \\
\hline Total (\$) & 6.13 & 6.66 & 0.53 & 8.6 & 5.82 & 6.75 & 0.93 & 16.0 & -0.40 & 0.068 \\
\hline
\end{tabular}


Effect on Drug Utilization and Expenditures of a

Cost-Share Change From Copayment to Coinsurance

\section{6c. SSRIs/SNRIS}

\begin{tabular}{|c|c|c|c|c|c|c|c|c|c|c|}
\hline \multirow[b]{2}{*}{ All Tiers } & \multicolumn{4}{|c|}{$\begin{array}{c}\text { Intervention } \\
(\mathrm{n}=3,257)\end{array}$} & \multicolumn{4}{|c|}{$\begin{array}{c}\text { Comparison } \\
(\mathrm{n}=456)\end{array}$} & \multirow[t]{2}{*}{ DD } & \multirow[t]{2}{*}{$\begin{array}{c}\text { Wilcoxon } \\
P \text { Value } \\
\end{array}$} \\
\hline & Pre & Post & Change & $\%$ & Pre & Post & Change & $\%$ & & \\
\hline Utilization (days) & 22.54 & 22.77 & 0.23 & 1.0 & 21.63 & 23.12 & 1.49 & 6.9 & -1.26 & 0.010 \\
\hline Patient OOP (\$) & 16.61 & 19.18 & 2.56 & 15.4 & 16.85 & 17.95 & 1.10 & 6.5 & 1.46 & 0.197 \\
\hline Employer (\$) & 39.95 & 39.66 & -0.28 & -0.7 & 38.86 & 42.75 & 3.89 & 10.0 & -4.17 & $<0.001$ \\
\hline Total (\$) & 56.59 & 58.87 & 2.28 & 4.0 & 55.71 & 60.69 & 4.99 & 9.0 & -2.71 & 0.004 \\
\hline
\end{tabular}

Tier 1

\begin{tabular}{l|r|r|r|r|r|r|r|r|r|r}
\hline Utilization (days) & 7.39 & 7.71 & 0.33 & 4.5 & 6.85 & 7.52 & 0.67 & 9.8 & -0.35 & 0.254 \\
\hline Patient OOP (\$) & 2.31 & 2.23 & -0.07 & -3.0 & 2.20 & 2.39 & 0.19 & 8.6 & -0.26 & $<0.001$ \\
\hline Employer (\$) & 6.48 & 6.12 & -0.37 & -5.7 & 6.98 & 5.74 & -1.24 & -17.8 & 0.88 & 0.001 \\
\hline Total (\$) & 8.79 & 8.35 & -0.44 & -5.0 & 9.18 & 8.13 & -1.05 & -11.4 & 0.61 & 0.407 \\
\hline
\end{tabular}

Tier 2

\begin{tabular}{l|r|r|r|r|r|r|r|r|r|r}
\hline Utilization (days) & 10.85 & 10.66 & -0.19 & -0.9 & 10.29 & 10.71 & 0.42 & 4.1 & -0.61 & 0.092 \\
\hline Patient OOP (\$) & 8.80 & 9.85 & 1.05 & 11.9 & 8.64 & 8.97 & 0.33 & 3.8 & 0.72 & 0.139 \\
\hline Employer (\$) & 28.02 & 28.24 & 0.21 & 0.7 & 26.29 & 29.08 & 2.79 & 10.6 & -2.58 & 0.011 \\
\hline Total (\$) & 36.82 & 38.09 & 1.26 & 3.4 & 34.93 & 38.05 & 3.12 & 8.9 & -1.85 & 0.064 \\
\hline
\end{tabular}

Tier 3

\begin{tabular}{l|r|r|r|r|r|r|r|r|r|r}
\hline Utilization (days) & 4.29 & 4.39 & 0.09 & 2.1 & 4.49 & $4 . .89$ & 0.40 & 8.9 & -0.31 & 0.300 \\
\hline Patient OOP (\$) & 5.50 & 7.09 & 1.59 & 28.9 & 6.00 & 6.58 & 0.58 & 9.7 & 1.01 & 0.004 \\
\hline Employer (\$) & 5.44 & 5.31 & -0.13 & -2.4 & 5.59 & 7.93 & 2.34 & 41.9 & -2.47 & $<0.001$ \\
\hline Total (\$) & 10.97 & 12.43 & 1.45 & 13.2 & 11.59 & 14.51 & 2.92 & 25.2 & -1.47 & 0.013 \\
\hline
\end{tabular}

\section{6d. Statins}

\begin{tabular}{|c|c|c|c|c|c|c|c|c|c|c|}
\hline \multirow[b]{2}{*}{ All Tiers } & \multicolumn{4}{|c|}{$\begin{array}{c}\text { Intervention } \\
(\mathrm{n}=3,981)\end{array}$} & \multicolumn{4}{|c|}{$\begin{array}{c}\text { Comparison } \\
(\mathrm{n}=627)\end{array}$} & \multirow[t]{2}{*}{ DD } & \multirow[t]{2}{*}{$\begin{array}{c}\text { Wilcoxon } \dagger \\
\text { P Value } \\
\end{array}$} \\
\hline & Pre & Post & Change & $\%$ & Pre & Post & Change & $\%$ & & \\
\hline Utilization (days) & 23.07 & 23.91 & 0.83 & 3.6 & 21.86 & 23.57 & 1.70 & 7.8 & -0.87 & 0.038 \\
\hline Patient OOP (\$) & 20.20 & 23.66 & 3.45 & 17.1 & 19.84 & 21.39 & 1.55 & 7.8 & 1.90 & $<0.001$ \\
\hline Employer (\$) & 46.60 & 48.21 & 1.61 & 3.5 & 43.38 & 50.00 & 6.62 & 15.3 & -5.00 & $<0.001$ \\
\hline Total (\$) & 66.80 & 71.87 & 5.07 & 7.6 & 63.22 & 71.39 & 8.17 & 12.9 & -3.10 & 0.015 \\
\hline
\end{tabular}

Tier 1

\begin{tabular}{l|c|c|c|c|c|c|c|c|c|c}
\hline Utilization (days) & 0.50 & 0.55 & 0.05 & 0.1 & 0.66 & 0.82 & 0.16 & 24.2 & -0.11 & 0.646 \\
\hline Patient OOP (\$) & 0.17 & 0.21 & 0.04 & 23.5 & 0.22 & 0.27 & 0.05 & 22.7 & 0.02 & 0.950 \\
\hline Employer (\$) & 0.66 & 0.63 & -0.03 & -4.5 & 0.76 & 0.88 & 0.12 & 15.8 & -0.15 & 0.522 \\
\hline Total (\$) & 0.83 & 0.84 & 0.01 & 1.2 & 0.98 & 1.16 & 0.17 & 17.3 & -0.16 & 0.700 \\
\hline
\end{tabular}

Tier 2

\begin{tabular}{l|r|r|r|r|r|r|r|r|c|c}
\hline Utilization (days) & 18.58 & 19.38 & 0.80 & 4.3 & 17.29 & 18.41 & 1.11 & 6.4 & -0.31 & 0.368 \\
\hline Patient OOP $(\$)$ & 14.98 & 16.68 & 1.70 & 11.3 & 14.40 & 15.29 & 0.89 & 6.2 & 0.81 & $<0.001$ \\
\hline Employer $(\$)$ & 39.33 & 42.23 & 2.91 & 7.4 & 36.14 & 40.85 & 4.71 & 13.0 & -1.80 & 0.030 \\
\hline Total $(\$)$ & 54.31 & 58.92 & 4.61 & 8.5 & 50.55 & 56.14 & 5.60 & 11.1 & -0.99 & 0.639 \\
\hline
\end{tabular}

Tier 3

\begin{tabular}{|c|c|c|c|c|c|c|c|c|c|c|}
\hline Utilization (days) & 3.99 & 3.97 & -0.03 & 0.8 & 3.91 & 4.34 & 0.42 & 10.7 & -0.45 & 0.029 \\
\hline Patient OOP (\$) & 5.05 & 6.77 & 1.71 & 33.9 & 5.21 & 5.82 & 0.61 & 11.7 & 1.10 & $<0.001$ \\
\hline Employer (\$) & 6.61 & 5.34 & -1.26 & -19.1 & 6.48 & 8.27 & 1.79 & 27.6 & -3.05 & $<0.001$ \\
\hline Total (\$) & 11.66 & 12.11 & 0.45 & 3.6 & 11.69 & 14.09 & 2.40 & 20.5 & -1.95 & 0.046 \\
\hline \multirow{2}{*}{\multicolumn{11}{|c|}{$\begin{array}{l}\text { * Discrepancies in the difference-in-difference calculation are due to rounding. } \\
+ \text { The Wilcoxon rank sum test was used to compare the } 2 \text { groups. }\end{array}$}} \\
\hline & & & & & & & & & & \\
\hline \multicolumn{11}{|c|}{$\begin{array}{l}\text { Percentages refer to the percentage change from the pre-change to the post-change period. Pre-change period=October 1, 2004, through March } 31,2005 \\
\text { post-change period=October 1,2005, through March 31, 2006. Utilization is days supply. }\end{array}$} \\
\hline \multicolumn{11}{|c|}{$\begin{array}{l}D D=\text { the difference-in-difference estimate; } O O P=\text { out-of-pocket; } P P P M=\text { per patient per month; SNRI=selective norephinephrine reuptake inhibitor; } \\
\text { SSRI=selective serotonin reuptake inhibitor. }\end{array}$} \\
\hline
\end{tabular}


Employer group expenditures increased for all 3 classes in the comparison group, but they decreased for the SSRIs/SNRIs in the intervention group. The amount of increase in employer spending was higher in the intervention group (\$2.66 PPPM) than in the comparison group ( $\$ 2.46$ PPPM) for antihypertensives but was lower for statins in the intervention group (\$1.61 PPPM) than in the comparison group (\$6.62 PPPM). While the comparison group experienced increases in employer expenditures for tier-3 medications in all classes, employer spending per month decreased in the intervention group for all 3 classes.

Total spending increased for both groups for all 3 classes, but the increases in SSRI/SNRI and statin spending were smaller for the intervention group than for the comparison group. In both of those classes, the intervention group experienced smaller increases in spending on tier-3 medications than did the comparison group.

\section{Discussion}

Our results indicate that changing from a 3-tier copayment benefit design to a 4-tier coinsurance benefit design slowed the growth of total PMPM expenditures overall (for all drug classes) and the growth of PPPM utilization and expenditures for 3 classes of essential medications but did not have a significant impact on overall PMPM utilization. Ours is the first study to compare the effect of a copayment to coinsurance design change in a privately insured group against a parallel comparison group. Previous studies evaluated the effect of the change to coinsurance, and showed no change in utilization ${ }^{13,29-32}$ or a decrease in essential medication utilization. ${ }^{15}$ However, these studies were conducted with an older population or lower cost-share before intervention. The results of our study are consistent with a previous pre-post comparator study that examined a benefit change from 2-tier to 3-tier design on prescription drug and medical utilization and cost. ${ }^{24}$ That study demonstrated increases in prescription drug utilization after the plan change in both the intervention and comparison groups with a slower rate of utilization growth in the intervention group and did not find an increase in medical services utilization. Since our study observed similar prescription utilization patterns, it may be that outcomes were not negatively affected.

The coinsurance design implemented during this study maintained the tier system used in the typical 3-tier copayment structure for most drug classes. The exception, as discussed previously, is that all biologic medications were moved to a 4th copayment tier. As would be expected for a benefit change that shifts more cost to the patient, the employer group expenditures were favorably affected while the patient experienced a slightly greater increase in OOP spending.

We expected that additional cost-sharing for more expensive medications would lead to a shift in utilization from the most expensive copayment tier (tier 3 ) to the less expensive tiers (tiers
1 and 2) as well as a shift to less expensive medications within each tier. Such a shift should reduce overall medication spending relative to a fixed-dollar copayment design. However, we also recognized the possibility that patients on tier-3 medications during the pre-change period had already accepted a higher OOP cost for their medications and therefore would be less price sensitive than would patients using medications in lower tiers.

It is possible that switching behavior for patients taking tier-2 and tier-3 medications is influenced directly by the cost-share of medications that they are currently taking. Patient OOP spending for tier-3 medications increased more for the intervention group than for the comparison group, which may have stabilized utilization in the intervention group. The stable utilization of tier-3 medications in the intervention group compares favorably with the small growth in utilization observed in the comparison group. It is likely that the previous 3-tier copayment design had already caused a reduction in the use of tier-3 medications. One may also expect that following an increase in patient OOP, plan participants may choose to discontinue use of those medications or file claims with another insurance carrier if one is available within their family. The rates of discontinuation in filling prescriptions in both groups after the intervention date were similar in that approximately equal proportions of patients with preperiod utilization were excluded for lack of post-period utilization (Figure).

For the antihypertensive medications, with widely used generics we found that patient OOP decreased and employer cost increased as patients on tier-1 medications experienced a decrease in their cost-sharing; however, utilization of tier-1 antihypertensive medications was not affected. This is promising for this class, as Taira et al. found that greater compliance was associated with lower copayment levels. ${ }^{35}$ On the other hand, OOP spending for tier-3 medications increased more for the intervention group than for the comparison group and the rate of tier-3 utilization growth was contained.

We did not find a decrease in overall utilization or expenditures in the SSRI/SNRI class, but the rate of growth was below that of the comparison group. Goldman et al. examined the predicted effect on SSRI utilization of doubling copayments for privately insured beneficiaries using a statistical model..$^{10}$ Their study predicted that antidepressant utilization among depressed patients would decrease and utilization of other medications would decline even more. Landsman et al. observed a greater discontinuation rate and lower medication possession ratio for SSRIs following the implementation of higher cost-sharing levels. ${ }^{8}$ Unlike the previous studies, our study was conducted at a time when generics were available for the SSRI class. Patients on generic medications experienced a decrease in patient OOP spending, so that they would be less likely to discontinue their medications.

The statin medications demonstrated the largest increase in patient expenditures due in part to the lack of widely used 
generic medications at the time of this study. Overall utilization of statin medications did not increase as much in the intervention group as in the comparison group. This is consistent with previous estimates by Gibson et al., who found that continuing users of chronic medications are insensitive to price in responding to copayment increases. ${ }^{5}$ However, Landsman et al. observed that following implementation of a change from a 2-tier to 3-tier benefit, the statin discontinuation rate was higher in the group that changed benefits than in a comparison group. ${ }^{8}$ The discrepancy between Landsman et al.'s findings and our results may be due to differences in cost-sharing amounts; Landsman et al.'s sample likely experienced larger average cost-sharing change than did our sample due to the much larger utilization for formulary statins in our plans. As more statins become available generically and those generics become less expensive, it is likely that the effect of a coinsurance design implementation will be similar to that seen with the antihypertensive medications in the present study.

The minimum/maximum cost-sharing amount for each claim is important to note. As mentioned previously, the reason for the minimum is to ensure sufficient OOP cost differentiation between generics and preferred and non-preferred brand medications. The maximum limits were set to maintain the tiered differentiation and to limit the member cost-share for expensive medications. The decrease in patient cost-share for tier-1 medications in the intervention group can be attributed to the difference from a $\$ 10$ copayment to coinsurance with a $\$ 5$ minimum. However, providing incentives to the patient to use generics because they may cost less is a proactive benefit design. Benefit designs that utilize a different minimum/maximum dollar schedule or no minimum/ maximum caps may have different results when switching from copayments to coinsurance.

A coinsurance benefit design has potential advantages over a dollar copayment design for both plan sponsors and beneficiaries. For plan sponsors, the coinsurance method of computing member cost-share adjusts automatically to rising drug prices, maintaining the member cost-share at the specified proportion (e.g., 20\%) over time. In addition, the coinsurance design ensures that the member is aware of the actual price of the drug. This awareness of actual price has the potential to more effectively engage beneficiaries in the cost outcomes of drug therapy choices compared with fixed-dollar copayments. However, while coinsurance eliminates the need for the health plan to update the copayment dollar amounts over time, the beneficiary does not know the amount of the cost-share until the point of care when the pharmacy claim is submitted for adjudication and the coinsurance percentage is applied to the allowed charge.

\section{Limitations}

There are several limitations to our study. First, the study population was selected from privately insured groups in 1 state, and their results may not generalize to other populations. Second, our study population consisted of patients accustomed to a 3-tier copayment structure for pharmacy benefits. The observed effect on patients moving from other benefit designs may be different. Third, medical claims were not examined to monitor for an increase or decrease in medical utilization or expenditures. Since we found only a $4.1 \%$ increase in utilization of 3 essential medication classes in the intervention group and no significant change in overall utilization of all drugs following this benefit design change, it is unlikely that adverse outcomes like those observed in Tamblyn et al. have occurred. ${ }^{15}$ Our study examined 3 essential medication classes chosen in part because they represent a significant portion of the employer groups' medication spending. However, in our PMPM analysis of utilization for all drug classes, the intervention and comparison groups did not significantly differ in the increase in drug utilization from the pre-change period to the post-change period.

Fourth, it is possible that increases to the tiered copayment amounts could have achieved a similar outcome without implementing coinsurance, though such a change would not provide some of the other benefits associated with a coinsurance design. Similarly, it is possible that a coinsurance structure that significantly increased patient OOP costs would have produced different results. Finally, further research is needed to ferret out the effects of the magnitude of cost-share change from the type of cost-share change. In the present study, the change from 3-tier copayment to 4-tier coinsurance resulted in essentially no change in the average member cost-share, $31.5 \%$ in the pre-change period versus $31.8 \%$ in the post-change period (Table 3). The comparison group had very similar overall member cost-share in both periods, an average of $33.5 \%$ in the pre-change period versus $31.5 \%$ in the post-change period.

\section{Conclusions}

While this study showed that a coinsurance design can control utilization and spending for certain classes of medications, additional questions need to be answered about this benefit design. Future research should examine the effects of a switch to coinsurance on medical utilization, expenditures, and health outcomes. Additionally, studies that include a wider range of medication classes, including acute and chronic medications, are needed. Studies conducted in populations moving from something other than a 3-tier copayment design and studies examining various coinsurance rates and minimum/maximum OOP levels are needed as well. The present study assessed the short-term effects on utilization and costs overall (member and plan sponsor) of a coinsurance versus a 3-tier copayment plan design in which the average member cost-share was similar for the 2 groups.

The copayment to coinsurance benefit design change explored in this study did help contain the rise in medication cost trend. The coinsurance model with strategically aligned minimums 
may provide an added incentive to use less expensive generic medications, as patient expenditures for tier- 1 medications may decrease after the benefit design change. Coinsurance provides an option to employer groups and insurers interested in controlling medication spending without decreasing utilization.

\section{Authors}

Donald G. Klepser is an assistant professor, Department of Pharmacy Practice, University of Nebraska Medical Center, Omaha; and Jeffrey R. Huether is a managed care pharmacy resident; Lee J. Handke is vice president, Health Network and Wellness Services; and Clint E. Williams is director of pharmacy, Blue Cross and Blue Shield of Nebraska, Omaha.

AUTHOR CORRESPONDENCE: Donald G. Klepser, PhD, MBA, Assistant Professor, Department of Pharmacy Practice, University of Nebraska Medical Center College of Pharmacy, 986045 Nebraska Medical Center, Omaha, NE 68198-6045. Tel.: 402.559.4927; Fax: 402.559.5673; E-mail:dklepser@unmc.edu

\section{ACKNOWLEDGMENTS}

The authors thank Jeffrey Olson, MSEd, Blue Cross and Blue Shield of Nebraska, for his assistance with this research.

\section{DISCLOSURES}

The authors report no conflicts of interest related to this subject and no external funding for this research. This research was presented in part as a poster abstract at the 19th Annual Meeting of the Academy of Managed Care Pharmacy in San Diego, California, in April 2007. The poster abstract is available on page 179 of the March 2007 issue of JMCP at http://www.amcp org/data/jmcp/pl63-211.pdf.

Donald Klepser was primarily responsible for the study concept and design, with input from all the authors; Jeffrey Huether, Lee Handke, and Clint Williams were primarily responsible for data collection; and data interpretation, writing, and revision of the manuscript were primarily the work of Klepser and Huether, with input from the other authors.

\section{REFERENCES}

1. Centers for Medicare \& Medicaid Services. National health expenditure data. Historical highlights (2004). Available at: www.cms.hhs.gov/ NationalHealthExpendData/downloads/highlights.pdf. Accessed July 25, 2006.

2. Centers for Medicare \& Medicaid Services. National health expenditure data. Historical highlights (2005). Available at: www.cms.hhs.gov/ NationalHealthExpendData/downloads/highlights.pdf. Accessed February 12, 2007.

3. Gibson TB, Ozminkowski RJ, Goetzel RZ. The effects of prescription drug cost sharing: a review of the evidence. Am J Manag Care. 2005;11(11):730-40.

4. Gibson TB, Mark TL, Axelsen K, Baser O, Rublee DA, McGuigan KA. Impact of statin copayments on adherence and medical care utilization and expenditures. Am J Manag Care. December 2006;12(special issue):SP11-SP19.
5. Gibson TB, Mark TL, McGuigan KA, Axelsen K, Wang S. The effects of prescription drug copayments on statin adherence. Am J Manag Care. 2006;12(9):509-17.

6. Gibson TB, McLaughlin CG, Smith DG. A copayment increase for prescription drugs: the long-term and short-term effects on use and expenditures. Inquiry. 2005;42(3):293-310.

7. Huskamp HA, Deverka PA, Epstein AM, et al. Impact of 3-tier formularies on drug treatment of attention-deficit/hyperactivity disorder in children. Arch Gen Psychiatry. 2005;62(4):435-41.

8. Landsman PB, Yu W, Liu X, Teutsch SM, Berger ML. Impact of 3-tier pharmacy benefit design and increased consumer cost-sharing on drug utilization. Am J Manag Care. 2005;11(10):621-28.

9. Roblin DW, Platt R, Goodman MJ, et al. Effect of increased cost sharing on oral hypoglycemic use in five managed care organizations: how much is too much? Med Care. 2005;43(10):951-59.

10. Goldman DP, Joyce GF, Escarce JJ, et al. Pharmacy benefits and the use of drugs by the chronically ill. JAMA. 2004;291(19):2344-50.

11. Kamal-Bahl S, Briesacher B. How do incentive-based formularies influence drug selection and spending for hypertension? Health Aff (Millwood). 2004;23(1):227-36

12. Lurk JT, DeJong DJ, Woods TM, Knell ME, Carroll CA. Effects of changes in patient cost sharing and drug sample policies on prescription drug costs and utilization in a safety-net-provider setting. Am J Health-Syst Pharm. 2004:61(3):267-72.

13. Blais L, Couture J, Rahme E, LeLorier J. Impact of a cost sharing drug insurance plan on drug utilization among individuals receiving social assistance. Health Policy. 2003;64(2):163-72.

14. Huskamp HA, Deverka PA, Epstein AM, Epstein RS, McGuigan KA, Frank RG. The effect of incentive-based formularies on prescription-drug utilization and spending. N Engl J Med. 2003;349(23):2224-32.

15. Tamblyn R, Laprise R, Hanley JA, et al. Adverse events associated with prescription drug cost-sharing among poor and elderly persons. JAMA. 2001;285(4):421-29.

16. Johnson RE, Goodman MJ, Hornbrook MC, Eldredge MB. The effect of increased prescription drug cost-sharing on medical care utilization and expenses of elderly health maintenance organization members. Med Care. 1997;35(11):1119-31.

17. Johnson RE, Goodman MJ, Hornbrook MC, Eldredge MB. The impact of increasing patient prescription drug cost sharing on therapeutic classes of drugs received and on the health status of elderly HMO members. Health Services Research. 1997;32(1):103-22.

18. Smith DG. The effects of copayments and generic substitution on the use and costs of prescription drugs. Inquiry. 1993;30(2):189-98.

19. Harris BL, Stergachis A, Ried LD. The effect of drug co-payments on utilization and cost of pharmaceuticals in a health maintenance organization. Med Care. 1990;28(10):907-17.

20. Foxman B, Valdez RB, Lohr KN, Goldberg GA, Newhouse JP, Brook $\mathrm{RH}$. The effect of cost sharing on the use of antibiotics in ambulatory care: results from a population-based randomized controlled trial. J Chronic Dis. 1987:40(5):429-37.

21. Leibowitz A, Manning WG, Newhouse JP. The demand for prescription drugs as a function of cost sharing. Soc Sci Med. 1985;21(10):1063-69.

22. Joyce GF, Escarce JJ, Solomon MD, Goldman DP. Employer drug benefit plans and spending on prescription drugs. JAMA. 2002;288(14):1733-39.

23. Fairman KA, Motheral BR, Henderson RR. Retrospective, long-term follow-up study of the effect of a three-tier prescription drug copayment system on pharmaceutical and other medical utilization and costs. Clin Ther. 2003;25(12):3147-66.

24. Motheral B, Fairman KA. Effect of a three-tier prescription copay on pharmaceutical and other medical utilization. Med Care.

2001;39(12):1293-304. 
25. Nair KV, Wolfe P, Valuck RJ, McCollum MM, Ganther JM, Lewis SJ. Effects of a 3-tier pharmacy benefit design on the prescription purchasing behavior of individuals with chronic disease. J Manag Care Pharm. 2003;9(2):123-33. Available at: www.amcp.org/data/jmcp/Research123-133.pdf.

26. Rector TS, Finch MD, Danzon PM, Pauly MV, Manda BS. Effect of tiered prescription copayments on the use of preferred brand medications. Med Care. 2003;41(3):398-406.

27. Thomas CP, Wallack SS, Lee S, Ritter GA. Impact of health plan design and management on retirees' prescription drug use and spending, 2001. Health Aff (Millwood). Jul/Dec 2002;suppl Web exclusives:W408-19.

28. Landon BE, Rosenthal MB, Normand ST, et al. Incentive formularies and changes in prescription drug spending. Am J Manag Care. 2007; 13(part 2):360-69

29. Blais L, Boucher JM, Couture J, Rahme E, LeLorier J. Impact of a cost-sharing drug insurance plan on drug utilization among older people. J Am Geriatr Soc. 2001;49(4):410-14.

30. Pilote L, Beck C, Richard H, Eisenberg MJ. The effects of cost-sharing on essential drug prescriptions, utilization of medical care and outcomes after acute myocardial infarction in elderly patients. CMAJ. 2002;167(3):246-52.
31. Karter AJ, Parker MM, Moffet HH, et al. Effect of cost-sharing changes on self-monitoring of blood glucose. Am J Manag Care. 2007;13(7):408-16.

32. Schneeweiss S, Patrick AR, Maclure M, Dormuth CR, Glynn RJ. Adherence to $\beta$-blocker therapy under drug cost-sharing in patients with and without acute myocardial infarction. Am J Manag Care. 2007;13(8): 445-52.

33. Huether JR, Klepser DG, Handke LJ, Williams CE. Effect of cost-sharing change from copayment to coinsurance on multiple sclerosis specialty drug expenditures and utilization. Poster presented at: 2007 AMCP Annual Meeting and Showcase; April 11-14, 2007; San Diego, CA. Available on page 179 at: www.amcp.org/data/jmcp/p163-21l.pdf.

34. Von Korff M, Wagner EH, Saunders K. A chronic disease score from automated pharmacy data. J Clin Epidemiol. 1992;45(2):197-203.

35. Taira DA, Wong KS, Frech-Tamas F, Chung RS. Copayment level and compliance with antihypertensive medication: analysis and policy implications for managed care. Am J Manag Care. 2006;12(11):678-83. 